\title{
A campanha contra a "lepra" no Brasil e em Santa Catarina: entre a filantropia e a exclusão social dos filhos sadios de enfermos*
}

\author{
The campaign of anti leprosy in Brazil and Santa Catarina: \\ between philanthropy and social exclusion of healthy children of lepers
}

Débora Michels Mattos

Doutora em História pela Universidade de São Paulo dmattos@usp.br

\begin{abstract}
Resumo: Este artigo objetiva demonstrar como se deu a implantação da campanha contra "lepra" no Brasil, na primeira metade do século XX. Ele privilegia, no âmbito da região catarinense, a consolidação de estratégias de ação que visavam, essencialmente, dedicar-se ao problema da prole sadia dos enfermos. Essas estratégias se apoiaram em preceitos médicos e de filantropia. Nesse sentido, ele analisa a constituição de uma entidade, a Sociedade de Assistência aos Lázaros e Defesa contra a Lepra de Santa Catarina, no plano de profilaxia e erradicação da hanseníase que foi personificado através de uma instituição preventorial, o Educandário Santa Catarina, local para a exclusão de centenas de crianças e adolescentes saudáveis, a partir da década de 1940.
\end{abstract}

Palavras-chave: "Lepra", Campanha contra a "lepra”, Profilaxia, Filantropia, Exclusão.

\begin{abstract}
This article aims to show how was the implementation of the anti leprosy campaign in Brazil in the first half of the twentieth century. It focuses, on the Santa Catarina region, the action strategies aimed essentially dedicate to the problem of healthy offspring of the sick. These strategies are supported in medical and philanthropy preceptes. In this sense, it analyzes the formation of an entity, the "Sociedade de Assistência aos Lázaros e Defesa contra a Lepra de Santa Catarina", in the prophylaxis plan and eradication of leprosy that was personified by a preventorial institution, the "Educandário Santa Catarina", place to the exclusion of hundreds of healthy children and adolescents, from the 1940s.
\end{abstract}

Keywords: Leprosy, Campaign of Anti leprosy, Prophylaxis, Philanthropy, Exclusion.

\footnotetext{
* Financiamento da pesquisa: Conselho Nacional de Desenvolvimento Científico e Tecnológico (CNPq)
} 


\section{O problema da "lepra" e a campanha nacional de combate à doença}

O sustentáculo para a implantação de um movimento nacional contra a "lepra", atual hanseníase ${ }^{1}$, foi lançado em princípios do século $\mathrm{XX}$, quando a constituição da saúde pública no Brasil passou a ser tomada como chave para o alcance do progresso nacional. A partir desse pressuposto, instituíram-se campanhas de cunho sanitário para resolver o problema das enfermidades de forma que o quadro de morbidez observado fosse diminuído ou cessado. Para isso, era necessário que o governo federal se empenhasse no suporte a medidas sanitárias. No entanto, elas foram pouco observadas até a década de 30, principalmente porque as questões que envolviam a saúde e as doenças, naquele contexto, estiveram vinculadas à importância que lhes era atribuída, geralmente, por cada chefe das unidades da federação (MATTOS, 2013).

No âmbito da "lepra", é fato que a sua incidência era tida como fonte de problema desde os tempos da Colônia e do Império. Porém, no contexto da República, passou a significar um obstáculo ao projeto de modernização do país, tornando-se objeto de interesse maior ao universo do poder público (HOCHMANN, 1998). Retrospectivamente, a década de 20 foi marcada pela criação do Departamento Nacional de Saúde Pública sob a direção de Carlos Chagas. Através dele foi criada a Inspetoria de Profilaxia da Lepra e Doenças Venéreas, cujas disposições estavam centradas na notificação obrigatória e no recenseamento da população enferma, na criação de asilos do tipo colônia agrícola para o confinamento dos doentes carentes de recursos, no isolamento domiciliar e sob vigilância dos mais abastados, no controle sobre os familiares e suspeitos de portar a doença, no internato dos recém-nascidos, na interdição à entrada de doentes de outros países, na notificação acerca de qualquer mudança residencial de portadores e parentes, na desinfecção pessoal e de tudo o que fosse manuseado por enfermos, na análise sobre as condições higiênicas dos lugares ocupados por eles, na proibição ao labor em atividades que ofereciam risco à saúde coletiva e, por fim, no veto à livre circulação em locais de grande convívio social, a

\footnotetext{
${ }^{1}$ Em 29 de março de 1995, através de Lei 9.010, o Brasil afirmou a proibição da expressão "lepra" e seus derivados nos documentos oficiais e órgãos públicos do país. Em substituição, passou a vigorar o uso da palavra "hanseníase" para a doença, e hanseniano ou portadores de hanseníase para os doentes. O propósito foi o de extinguir ou minorar os estigmas relacionados à enfermidade, geralmente inculcados sobre seus portadores, sendo Abraão Rotberg, médico hansenólogo vinculado à Organização Mundial de Saúde, principal responsável por essa mudança. Por se tratar de uma discussão histórica, a antiga denominação será utilizada, aqui, sempre entre aspas, devendo-se negar o emprego no âmbito da atualidade (ROTBERG, 1975; BRASIL, 1995; MATTOS, 2013).
} 
exemplo de jardins, praças, igrejas e comércios (QUEIROZ \& PUNTEL, 1997; MATTOS, 2013).

Conquanto que tais medidas tenham sido postas em prática apenas nos estados do Rio de Janeiro e São Paulo, foi no último que encontrou cenário mais favorável. Isso decorreu por causa da migração de grandes parcelas de trabalhadores rurais para o centro urbano-industrial, o que acarretou o seu crescimento populacional e, inevitavelmente, uma maior incidência de doenças, estando entre elas a "lepra".

Torna-se importante lembrar, além desses fatores, que São Paulo abrigava os mais proeminentes representantes da medicina moderna, em geral, afeitos à filosofia positivista de onde foi extraída a ideia de ordem e progresso, a exemplo de Heráclides Araújo e Aguiar Pupo. Aplicados no combate à enfermidade, reverberavam seus temores de forma articulada com pensadores, médicos e políticos de várias localidades brasileiras. Sustentavam suas teorias num modelo pensado por Oswaldo Cruz no alvorecer do século XX, qual seja, o das colônias agrícolas de confinamento. Como resultado, oportunizaram a construção de quatro instituições do gênero em território paulista: os asilos Santo Ângelo de Mogi das Cruzes (1928), Pirapitingui de Itu (1931), além de Cocais (1932) e Aimorés (1933), ambos situados no município de Bauru (MONTEIRO, 1995).

Inicialmente essas instituições foram construídas com verbas originárias dos setores públicos e privados. Mas na medida em que a campanha tomava corpo, foi aberto o leque de inferências sobre a necessidade de um maior envolvimento do governo federal.

Não é por falta de leis e regulamentos que se não extingue a lepra no Brasil. O que nos falta é a decisão dos governos! [...] A lepra não é para o Brasil apenas um gravíssimo problema médico-social; é também um sério problema econômico, que no futuro se tornará insolúvel. [...] Dinheiro não nos falta, pois gastam-se respeitáveis somas em obras públicas menos urgentes; também não nos faltam homens capazes de sacrificar a própria vida na realização de um ideal científico ou patriótico como esse. O que nos falta é uma determinação do governo para combater a lepra (ARAÚJO, 1929:7).

A máxima de que a saúde se configurava questão de Estado povoava o pensamento de médicos, juristas e outros intelectuais que simpatizavam com o desejo de 
que o Brasil fosse gerenciado por um governo nacionalista. Em relação aos profissionais da medicina, uma aliança com esse governo lhes oportunizava maior alargamento nas suas zonas de influência e, consequentemente, maior poder de classe, aspirações vislumbradas já em meados do século XIX (COSTA, 1985). No entanto, mesmo que os profissionais da saúde tomassem a Medicina Social como paradigma para fundamentar seus discursos, em que a profilaxia e o empenho pela restituição da saúde eram considerados o fio condutor para resolver o problema das doenças; acerca da "lepra" era definida outra trajetória. Ela terminava no asilo, no leprosário, nas instituições de exclusão que foram materializadas, via de regra, através dos hospitais-colônias. Seu objetivo estava fundado no afastamento social daquele que era visto como ameaça, portanto, na contramão do caminho que levava a cura ao doente para a sua posterior reinserção social (MACHADO et al., 1978; MONTEIRO, 1995; MATTOS, 2013).

Em termos de campanha, a divulgação, nos diversos meios de comunicação, sobre a importância de um movimento contra a "lepra" ser alçado no Brasil, figurou um dispositivo de apoio bastante eficaz. Durante a República Velha, o problema da doença era visto como algo à espera de solução, e isso por vários segmentos da sociedade. Nesse sentido, engendraram-se propostas amparadas em preceitos higiênicos e sanitaristas com o fito de assegurar a saúde coletiva a fim de salvaguardá-la dos males que afetavam o Brasil e provocavam o seu arrefecimento. Nesse cenário, reflexões inflamadas fortemente amparadas nas teorias eugenistas se aliavam a premissas moralizadoras e ações filantróprico-caritativas, sendo absorvidas pelas camadas mais afortunadas da sociedade (MATTOS, 2013). Na tela que se esboçava as instituições de cunho assistencial assumiram posição de destaque na medida em que as atividades que desenvolviam tencionavam agregar parcelas distintas da população rumo a um ideal comum: o de eliminar uma doença que colocava em risco o progresso da nação. Tal resultado só seria obtido por meio da promoção da assistência social ao enfermo, de sua família e principalmente de sua prole saudável (MATTOS, 2013).

Foi dessa tríade de intenções que em 1926 Alice Tibiriçá ${ }^{2}$ fundou a Sociedade de Assistência aos Lázaros e Defesa contra a Lepra. Entre seus membros constavam senhoras da elite paulistana e médicos envolvidos com o problema da enfermidade no

\footnotetext{
2 Alice Tibiriçá nasceu em Ouro Preto, no ano de 1886. Sua vida foi dedicada a atividades políticas e sociais. Representou a luta pela participação da mulher no âmbito de várias questões relativas à sociedade. Em São Paulo, foi precursora do movimento contra a hanseníase que adquiriu status nacional. Acreditava no progresso do país tendo por via a manutenção da saúde da sociedade. Foi fundadora do Instituto Carlos Chagas e em 1944 integrou a Federação de Combate à Tuberculose ao mesmo tempo em que continuou se dedicando ao problema da hanseníase (SHUMAHER \& BRAZIL, 2001).
} 
país. Em 1932 ela se transformou numa federação. Entre os seus objetivos estavam o “[...] combate sem interrupção, sem modificação, numa ação conjunta e uniforme, tendo por base os preceitos de higiene e, como finalidade, a assistência aos leprosos em seu longo calvário e, conjuntamente, a defesa dos sãos quanto ao perigo do contágio" (SOCIEDADE, 1929:3).

Conquanto que suas operações fossem de importante relevância para minimizar os danos que a "lepra" representava ao país, somente em 1935 se tornaram mais efetivas. Esse fato ocorreu quando Eunice Weaver assumiu a sua presidência. ${ }^{3}$ Esta, ao contrário de Tibiriçá, era alinhada com o modelo de tratamento pautado no isolamento e, portanto, mais próxima ao pensamento de parte significativa dos profissionais da saúde que estavam, ao lado do governo federal, envolvidos com a composição de estratégias de enfrentamento ao problema. De fato, foi quando Weaver abraçou o posto que a campanha contra a doença se tornou mais efetiva. Como desdobramento, aos poucos foi concretizado o plano para o confinamento compulsório dos enfermos em grandes hospitais-colônias e, ao seu lado, o internamento dos filhos sadios em instituições preventoriais (GOMIDE, 1991; MONTEIRO, 1995; MATTOS, 2013).

Cabe aqui salientar que desde a implantação do Departamento Nacional de Saúde Pública, quando São Paulo passou a se destacar no campo do cuidado com a "lepra", diferentes posições quanto aos meios de controle e combate se estabeleceram. Durante algum tempo, figuras contrárias ao isolamento compulsório indiscriminado, como Carlos Chagas e mesmo Alice Tibiriçá, estiveram à frente dos serviços considerados oficiais. Em linhas gerais defendiam que fossem adotadas medidas mais leves e menos traumáticas, como o tratamento ambulatorial ou domiciliar para os doentes, acompanhado de práticas de higiene. Para Tibiriçá, inclusive, o confinamento compulsório aumentava os estigmas acerca da doença (LEMOS, 1939; GOFFMAN, 1988).

Mas a tela pintada para o Brasil a partir dos anos 30, com a chegada de Getúlio Vargas ao poder e a dissolução do federalismo, encontrou espaço para o modelo fundado no alijamento. Isso porque a saúde passou a ser considerada elemento chave para a fomentação de uma sociedade forte, disciplinada, apta ao trabalho e capaz de

\footnotetext{
${ }^{3}$ Eunice Weaver era natural de São Manuel, São Paulo. Nasceu em 1904 e viveu em Piracicaba durante algum tempo. Casada com um professor que lecionava em uma universidade flutuante, experenciou o contato com portadores de hanseníase em locais com endemicidades conhecidas, como Havaí e Filipinas. Por volta dos anos 30, já no Brasil, aproximou-se da Sociedade de Assistência aos Lázaros de São Paulo, posterior Federação das Sociedades de Assistência aos Lázaros e Defesa contra a Lepra, permanecendo no posto por 15 anos (GIBSON, 1965).
} 
contribuir com o progresso do país, significando, a "lepra", um obstáculo.

Com efeito, os portadores eram vistos como pessoas potencialmente sem função social, já que as deformidades físicas decorrentes da doença os tornavam incapacitados ao trabalho, via de acesso ao desenvolvimento da nação. Sob tal aspecto, restava afastálos da sociedade sadia, impedindo que o "mal" de que eram portadores fosse transmitido aos demais. Para desonerar o Estado com a manutenção desses indivíduos, as colônias agrícolas eram bem-vindas, já que os recursos tirados para a sua subsistência seriam produzidos ali mesmo, no seu interior, através do labor de seus internos (MATTOS, 2013).

Com a criação do Departamento Nacional de Saúde e Assistência Médico-Social em 1934, criado a partir da reformulação do Departamento Nacional de Saúde Pública e apenso ao Ministério da Educação e Saúde Pública, a problemática da "lepra" foi priorizada no conjunto de ações tomadas para debelar as doenças que aumentavam o quadro de morbidez do Brasil. De 1934 a 1945 Gustavo Capanema assumiu a pasta do Ministério, dedicando-se, nos primeiros anos, à elaboração de uma reforma que visou contemplar, entre tantos assuntos, o problema da doença (HOCHMANN, 1998). Assim, o ano de 1936 assinalou a elaboração, por Ernani Agrícola, João de Barros e Joaquim Motta, de um texto que apontava para algumas providências. Para Santos, era preciso, primeiramente, coletar dados estatísticos sobre a incidência em cada estado, indicando “[...] quantos enfermos precisavam ser isolados, o número de leprosários que o país precisava ter, o custo de cada leito e a previsão de gastos com a construção das instalações necessárias" (SANTOS, 2006:95). O estudo serviu de fundamento à política adotada pela gestão Capanema. Foi absorvido, portanto, no projeto nacional que deu ao Ministério maior controle sobre as atividades relacionadas à saúde. O plano, integrado à chamada "Reforma Capanema" que foi instituída em 1937 através da criação de uma nova pasta denominada Ministério da Educação e Saúde, oportunizou a criação de Delegacias Federais de Saúde, ficando sob responsabilidade da União a promoção e a supervisão das atividades desenvolvidas no âmbito das unidades da federação (SANTOS, 2006).

No que se referiu à "lepra", esteve a cargo dos governos estaduais o gerenciamento dos leprosários do tipo hospitais-colônias, sendo da alçada das instituições filantrópicas a administração dos estabelecimentos preventoriais (SANTOS, 2006). Essas medidas relacionadas especificamente ao problema da doença foram acompanhadas do esquema de ação que foi elaborado pela Federação das Sociedades de 
Assistência aos Lázaros e Defesa contra a Lepra, quando Eunice Weaver se tornou presidente. De acordo ele e sob responsabilidade da Federação esteve "[...] a articulação de procedimentos para a obtenção de verbas à implantação do empreendimento que se detinha, sobretudo, à assistência social ao filho sadio do enfermo" (MATTOS, 2013:103). Porém, os fins contemplados em seus estatutos eram significativamente mais amplos:

a) Incrementar a fundação das Sociedades de Assistência aos Lázaros e Defesa contra a Lepra em todo o território nacional;

b) Incentivar a atividade dessas sociedades, promover a sua filiação, e colaborar com elas no seu programa de ação;

c) Promover campanhas financeiras em benefício das Sociedades filiadas, indenizando-se das despesas que faça com as mesmas;

d) Procurar obter a colaboração de outras organizações sociais, civis ou militares, especialmente as de caráter educacional;

e) Manter um órgão de publicidade intitulado "Revista de Combate à Lepra", sob a responsabilidade da Diretoria, tendo uma comissão de redação composta de três membros, com autoridades para eliminar da publicação quaisquer frases ou conceitos que possam ser considerados ofensivos ou inconvenientes;

f) Intervir nas resoluções de suas filiadas quando houver necessidade de corrigir injustiças ou afastar dificuldades, para melhorar e equilibrar a administração;

g) Propugnar pelo exame médico periódico, pelo menos para os domésticos, escolares e menores asilados;

h) Promover, periodicamente, conferências leprológicas nacionais ou regionais, enquanto a lepra for, no Brasil, o mais grave problema médicosocial (FEDERAÇÃO, 1935 apud GOMIDE, 1991:96-97).

Seguindo os Estatutos da Federação, engendrou-se, a partir disso, a efetiva campanha de combate à "lepra". Ela concentrou, também no filho sadio do enfermo, alvo de acurada atenção. De acordo com Mattos, por meio de "[...] publicações mensais, propagandas, panfletos, conferências e apelos, os membros da entidade iam aumentando a sua esfera de atuação e formando mais adeptos para a aplicação de suas propostas" (MATTOS, 2013:104). Tal fato foi evidenciado pelo número de Sociedades criadas no Brasil. Se até o ano de 1941 já haviam sido fundadas 59 em diferentes unidades da 
federação, em 1949 o país passou a contar com 80 (MATTOS, 2013).

O enunciado assistencialista ali presente externava os postulados eugenistas de preservação racial, demonstrando empatia com a filosofia nacionalista pensada para o país. Enfatizando que a edificação de uma nação forte só seria concretizada por meio da união, saúde e energia de seu povo, tornava-se imprescindível que a sociedade se comprometesse com o movimento (GOMIDE, 1991). Essa assertiva era estampada na imprensa, nos encontros, nos boletins e nos relatórios da entidade, e preconizava que o cuidado com os "filhos de Lázaros" devia ser praticado para o bem do Brasil.

O patriotismo que nos anima não esmorecerá porque somos brasileiras e a brasileiros ainda não se viu esmorecer em meio à peleja. A batalha está travada, e só há um caminho: o da vitória. Entoemos a marcha gloriosa de triunfo, rumo à proteção aos lázaros [...]. Longe de uma campanha racial e condenável, nós nos propusemos é bem de ver, a uma luta da raça. Mas de uma raça forte e sadia. [...] Salvando do contágio o filho do lázaro, damos aos pais infelizes a esperança de um futuro feliz e à sociedade restituiremos homens fortes capazes de cooperar para a grandeza do Brasil (SOCIEDADE, 1939:5).

Para conquistar adeptos, o uso da imprensa escrita se tornou importante recurso. Isso porque era comum, durante o Estado Novo, que ela fosse utilizada como instrumento para formar opiniões e orientar os desejos de grande parte da população (LENHARO, 1986). Acerca da "lepra”, a Federação de Assistência aos Lázaros fez uso dos jornais mais importantes e criou, a partir de 1936, a Revista de Combate à Lepra, em substituição aos boletins publicados desde 1929. Em suas páginas eram impressas as atividades realizadas no conjunto das Sociedades, as ações dos governos estaduais e da presidência da República, além de publicações científicas sobre a doença. Esse arsenal teve por meta fortalecer o programa projetado, mostrando o envolvimento de todos que sobre ele se imiscuíam. Assim, a Revista não apenas trazia publicações a respeito do filho sadio do enfermo. Elucidava, também, questões relativas aos modos de lidar com seus pais e todos aqueles que haviam sido acometidos com a doença (MONTEIRO, 1995; MATTOS, 2013).

No plano das seduções a figura feminina se tornou um dos mais proeminentes alvos. De fato, a mulher, a partir de argumentos que lhe conferiam o status de boa esposa e mãe de família, preparada naturalmente ao trato do lar, personificava a figura 
ideal para participar da campanha (RAGO, 1997). Para tanto, eram feitas alusões a atividades que elas eram hipoteticamente mestres em exercer, inculcando em suas mentes a importância de seus papéis nesse movimento de profilaxia e cuidado com a infância. Nesse sentido, mesmo que a Federação tratasse do problema da "lepra" sob perspectivas bem alargadas, era a prole sadia dos portadores o seu alvo principal. Assim, foi de sua atribuição a tomada de medidas para a salvaguarda dessa categoria de indivíduos (GOMIDE, 1991; MATTOS, 2013).

\section{Os filhos sadios de pais enfermos e a profilaxia da "lepra"}

Desde os anos 20 foi verificada, no Brasil, uma maior preocupação com o filho sadio dos portadores da "lepra". A temática da infância sadia enquanto chave para o desenvolvimento nacional reverberava na imprensa, em artigos acadêmicos, em pesquisas científicas e em conferências realizadas por estudiosos de diversas áreas do conhecimento. As transformações sociais, políticas e econômicas tidas no país, associadas ao crescimento urbano e industrial e à garantia da mão de obra, requeria um cuidado mais acentuado com a manutenção da vida daqueles que seriam futuros cidadãos e, portanto, habilitados a dar sua contribuição ao desenvolvimento do Brasil (RAGO, 1997; MATTOS, 2013) A partir dessas bases, os filhos saudáveis dos portadores da "lepra" se tornariam objetos de discursos. Nas suas composições, estariam presentes os postulados eugênicos de aperfeiçoamento de uma raça brasileira, já que o que se preconizava era o controle de indivíduos considerados uma ameaça ao plano de construção da nação, materializado na potência, no vigor e na perfeição de seu povo (MATTOS, 2013). Assim afirmava Rui Barbosa: "Uma criança que se perde, material ou moralmente, significa uma força que se perde para a sociedade" (BARBOSA, 1925:5).

Mesmo que a prole sadia do enfermo fosse considerada clinicamente saudável, era senso comum que não estivesse livre de desenvolver a doença. Nesse sentido, tornava-se virtualmente perigosa, configurando um risco a se evitar. Sob tal perspectiva, a Federação das Sociedades de Assistência aos Lázaros e Defesa contra a Lepra passou a se dedicar essencialmente a esse grupo de sujeitos, reconhecendo na construção de instituições preventoriais a solução ideal.

O regime de isolamento imputado aos enfermos tinha por resultado o abandono 
da família. Nesse cenário, os filhos eram os mais prejudicados, principalmente quando pai e mãe eram vítimas da doença. Mesmo que a "lepra" acometesse apenas um deles, o modelo de tratamento, pautando no confinamento, sucedia na desestruturação familiar, que se via desamparada e marcada por estigmas em função de seu vínculo com o doente. A partir dessa realidade, as instituições preventoriais atentariam para os mais vulneráveis providenciando o amparo àqueles que se encontravam relegados ao abandono, ou seja, a prole sadia. Tal modelo já havia sido posto em prática em outros lugares fora do Brasil, como Havaí, Índia e Filipinas. Conquanto que a Noruega tenha privilegiado a ajuda governamental a familiares que se incumbissem do cuidado da criança, no Brasil, a experiência norueguesa foi declinada, optando-se pelos preventórios enquanto instrumento mais eficiente em termos de profilaxia (ARAÚJO, 1929; MONTEIRO, 1995; GOMIDE, 1991; MATTOS, 2013).

Para alguns personagens que se dedicavam à problemática dos filhos sadios de portadores da "lepra", o recurso à instituição preventorial era tomada com recusa. Alice Tibiriçá considerava a internação como um reforço aos estigmas já que os internos inevitavelmente passavam a integrar uma categoria particular de pessoas afastadas do convívio social. Certamente, a renúncia, por parte da família, no provimento do amparo aos filhos de pais doentes, exacerbava os estigmas. Como resultado, imputava-se à prole saudável dos enfermos um sinal de diferença e preconceito que estava diretamente associado à doença (TIBIRIÇÁ, 1933; GOMIDE, 1991; MATTOS, 2013).

Mas embora essa realidade fosse vislumbrada, deu-se preferência à construção das instituições preventoriais. Apensas às que eram destinadas à segregação dos doentes e a outras voltadas ao controle dos casos suspeitos, deram materialidade ao modelo de tratamento idealizado. Para ele era preciso confinar os doentes em hospitais do tipo colônias agrícolas, internar os filhos sadios em abrigos preventoriais e monitorar possíveis portadores em dispensários locais. Sob essa perspectiva os poderes federal, estaduais e municipais, com o auxílio de iniciativas privadas e da Federação das Sociedades de Assistência aos Lázaros, passaram a atuar conjuntamente. Acerca dos preventórios, o papel da Federação foi decisivo, o que resultou no soerguimento de inúmeros prédios em todo o país, incluindo o estado catarinense, denominado Educandário Santa Catarina (MATTOS, 2013).

Retrospectivamente, a campanha de combate à enfermidade em Santa Catarina ocorreu através de um movimento engendrado por senhoras da elite florianopolitana que, inspiradas nas ações de outras regiões, iniciaram um movimento mais organizado 
tão logo fosse fundada uma afiliada da Federação. Tal fato aconteceu em 1936, após anos de discussões acerca da doença. Como temas de debates, salientava-se a indiferença do poder público na criação de estratégias para diminuir a incidência nessa localidade. Além disso, enfatizava-se que todo e qualquer tratamento dispensado ao doente provinha da assistência social, em geral, de instituições de ordem caritativa. No entanto, observava-se, ainda, práticas exclusivas de apartamento explicitamente severas e sem qualquer preocupação com o trato do enfermo. Isso porque, mesmo havendo indicações de que em Florianópolis eles fossem enviados a uma parte anexa do Hospital de Caridade, localizada um pouco abaixo de seu prédio principal e sob os cuidados das irmãs da Divina Providência, ao que tudo indica, não era incomum o seu encarceramento no sistema prisional. Nele, a Penitenciaria Estadual da Pedra Grande se destacou e assumiu o status, na década de 30, de um grande repositório de indesejáveis (POYER, 1999).

[...] todo o tipo de desviado que não se adequava aos padrões modernos e civilizatórios que as elites pretendiam instaurar na cidade, criminosos, menores abandonados e menores infratores, tuberculosos, leprosos e loucos, todos vivendo em conjunto, em um ambiente longe de ser considerado uma instituição moderna (POYER, 1999:180-181).

Com efeito, as transformações ocorridas no Brasil de fins do século XIX ao início do XX, sobretudo vinculadas ao processo de industrialização, exerceram entusiasmo nos representantes da elite local. Assim, a ideologia do progresso passou a integrar o conjunto de suas aspirações, sendo observadas já na Primeira República e assumindo maior robustez a partir do Estado Novo. Nesse cenário propício, as questões vinculadas à problemática da saúde e das doenças despertaram maior interesse, o que incentivou os debates em torno das temáticas da higiene, da educação e da moral. Em essência, seus porta-vozes objetivavam o exercício de ações que pudessem garantir o bem-estar da sociedade, tencionando, ao final, o progresso e a civilização (CHEREM, 1994; MATTOS, 2013).

Considerando progresso e civilização como bem valioso e supremo, investiase na higienização e salubridade, a instrução e tudo aquilo que se acreditava, constituíam-se os pontos fundantes dos perfis, dos comportamentos e das modernas práticas citadinas, caracterizadas por uma sociedade mais nova e 
avançada (CHEREM, 1994:8).

Para Cherem, o discurso alçado em torno da higiene e da saúde observava as pessoas enquanto células de um corpo, sendo este, representado pela sociedade. Sob tal perspectiva, o cuidado em relação aos seus membros era traduzido como a expressão máxima da harmonia, já que qualquer problema podia comprometer a estrutura social (CHEREM, 1994). Com base nisso, não apenas a capital de Santa Catarina passou a reverberar maior preocupação com a saúde, a higiene, a educação disciplinar e moral de seus moradores. Em todo o estado foram proferidos discursos em torno desses temas, considerados via de acesso ao progresso desejado (ARAÚJO, 1989; MATTOS, 2013).

Tal como em outros estados da União, a partir dos anos 30 a feitura de mecanismos voltados a dirimir os efeitos dos desajustes sociais se tornou mais efetiva. A ideologia eugenista foi aos poucos se cristalizando, sendo encampada por parcela significativa da população, além de alguns intelectuais e profissionais da saúde para os quais a doença, o abandono, o crime e a prostituição foram tomados como sérios empecilhos compleição de um tipo de cidadão "[...] forte, trabalhador e disciplinado, apto para o trabalho e agente do progresso da região" (MATTOS, 2013:112).

Objetivando frear os desarranjos que ameaçavam a harmonia pensada, o governo do estado de Santa Catarina, em conformidade com a política de Vargas, assumiu o compromisso de realizar uma série de investimentos, estando entre eles a construção do Hospital Colônia Santa Teresa, destinado ao confinamento compulsório dos doentes de "lepra" (MATTOS, 2013). Foi nesse contexto que a Federação das Sociedades de Assistência aos Lázaros e Defesa contra a Lepra providenciou a fundação de uma afiliada na capital de Santa Catarina, fato que permitiu a criação de um preventório para filhos sadios de "leprosos", inaugurado no ano de 1941.

Preliminarmente, a ação da Federação esteve amparada num movimento executado por membros da sociedade florianopolitana objetivando despertar o interesse comum ao problema da "lepra". Denominado Campanha da Solidariedade, foi iniciado em Florianópolis, a 5 de dezembro de 1936, sendo encerrado no dia 14. Como desdobramento as cidades de Laguna, Brusque, Blumenau, Joinville e Mafra aderiram à tarefa, espargindo suas ações para outros tantos municípios catarinenses onde mais Sociedades de Assistência foram fundadas. Entre seus membros, constavam mulheres das elites locais, educadores, homens públicos, empresários de destaque e médicos, para citar alguns exemplos, que se autodenominavam um "exército do bem" em proteção à 
preservação da raça (MATTOS, 2013). Porém, foi a figura feminina a mais significativa integrante, personificando o ideal de mulher engendrado pela burguesia em ascensão, qual seja, o de mãe de família (RAGO, 1997).

Das atividades conjecturadas para a Campanha da Solidariedade foram criados grupos de trabalho, cujas funções eram bem específicas. O primeiro, segundo e terceiro se dedicaram à comemoração de encerramento das atividades da campanha. A ideia era direcionar os lucros da festa à construção do preventório. O quarto e quinto se incumbiram de conseguir doações em dinheiro. Assim, seus integrantes percorreram as ruas da capital pedindo ajuda a pedestres, moradores e comerciantes. O sexto foi autorizado pelos governos estadual e municipal, a cobrar um pedágio aos passantes da ponte Hercílio Luz. Em troca, promoveram esclarecimentos sobre a doença, reforçando a importância de combatê-la. O sétimo, com ajuda do Clube Doze de Agosto, organizou um concurso de mesas “[...] para jantares e chás aos moldes de Paris, Roma e Rio de Janeiro, contendo todos os requisitos necessários, como louças, cristais e pratarias para a sua realização [...]" (A GAZETA, 1936b:4). Tanto os valores dos ingressos quanto do prêmio foram destinados aos fins da campanha, sendo as ações diariamente veiculadas na imprensa (FEDERAÇÃO, 1936; MATTOS, 2013).

Segundo Gomide, a divulgação das atividades realizadas pelas Sociedades de Assistência aos Lázaros através da imprensa era bastante vulgar e tencionava chamar o público leitor à adesão da campanha. Essa estratégia fazia movimentar, cada vez mais, grandes somas em dinheiro, o que colaborava para a construção dos abrigos preventoriais (GOMIDE, 1991). Em Santa Catarina, a temática da "lepra" era vista com significativa frequência e as atividades das Sociedades de Assistência aos Lázaros buscavam reforçar o sentido filantrópico presente em suas ações, exortando que todos deviam contribuir. Tendo a mulher como alvo privilegiado, sobretudo em função de um contexto favorável engendrado a partir dos movimentos feministas e do valor dado ao gênero no projeto de boa formação moral da infância, os pedidos de ajuda não se furtavam em fazer dela respeitável representante (MATTOS, 2013).

A mulher catarinense, possuidora de magnânimo e caritativo coração, solidariza-se e prestigia o nobilitante movimento de assistência aos filhos de leprosos (A GAZETA, 1936a:4).

A bandeira da caridade desfraldada em boa hora pela mulher catarinense, avança já de triunfo em triunfo, para a vitória definitiva, visando a 
construção de um preventório em Santa Catarina, para os menores descendentes dos infelizes do mal de Hansen (REPÚBLICA, 1936b:4).

Mas tais pedidos atingiam comumente outras categorias de indivíduos. Em verdade, não se distinguia quem deveria contribuir, o importante era a contribuição para que fosse solucionado um problema de grande envergadura, qual seja, o da "lepra" no Brasil, mácula ao projeto de soerguimento do país.

Catarinenses, alistai-vos no Exército da Solidariedade que visa extinguir para sempre no torrão pátrio o mal que nos deprime aos olhos dos povos civilizados e torna desgraçados e inúteis à economia do país milhares de patrícios nossos (REPÚBLICA, 1936a:3).

Ao lado desse clamor eloquente, a imprensa também publicava artigos acerca da doença, em geral, voltados ao esclarecimento sobre o sentido da campanha, especialmente buscando discorrer, a partir de bases tomadas como científicas ou ideológicas, sobre o problema da prole sadia dos enfermos. Nas falas apresentadas, médicos e eugenistas tinham espaço reservado, reforçando um pânico coletivo atrelado à possibilidade de um contágio efetivamente improvável.

Na prática, muito pouco se sabia sobre as formas de transmissão da doença, sendo ela incurável. Em 1872 o médico norueguês Armauer Hansen descobriu o seu agente causador, o mycobacterium leprae, fato que comprovou o seu caráter infectocontagioso. Porém, não cessaram os posicionamentos que discordavam dessa teoria e insistiam na ideia da hereditariedade (MONTEIRO, 1995). Acerca dos filhos saudáveis, temia-se que pudessem desenvolvê-la, transmitindo-a silenciosamente até que os primeiros sintomas viessem a aparecer. Nesse sentido, afastá-los do convívio com os demais era considerado medida profilática, apesar de experiências já terem demonstrado nula possibilidade. Isso porque a hanseníase, então denominada "lepra", só se torna transmissível nos estágios em que há uma alta quantidade de bacilos, comprovado por um número superior a cinco lesões de pele de nula sensibilidade. Esse fato já era sabido na década de 40, impossibilitando que pessoas assintomáticas fossem veiculadoras potenciais. No entanto, apelava-se ao que estivesse à mão, dando-se espaço ao afloramento dos temores mais íntimos (MONTEIRO, 1995; MATTOS 2013).

Um mal invadiu o Brasil de Norte a Sul, a lepra, que em sua hediondês 
nenhum mal a supera, e ei-lo que livremente penetra nos lares felizes, transformando a alegria das afeições mais caras em cruel suplício. A lepra, quando imprime seu estigma nas criaturas, apaga para sempre os sorrisos dos lábios daqueles que lhe são caros. Quem poderá sentir-se feliz ao saber que tem um dos seus entes mais queridos atacado pelo mal horrível que deforma e faz cair em vida os pedaços de carne flagelada? [...] Não é possível, pois, que as mães do Brasil recusem sua cooperação para a solução do problema que tende a preservar o seu filho do alcance da terrível moléstia. [...] São circunstantes do leproso; não devem frequentar escolas em promiscuidade com outras crianças, pois que novos focos podem surgir entre esses que conviveram longos anos com os pais enfermos (REPÚBLICA, 1936a:3).

O movimento encabeçado através da Campanha da Solidariedade e a fundação da Sociedade de Assistência aos Lázaros na capital de Santa Catarina, espargida para outras tantas localidades catarinenses, resultaram no aumento das verbas angariadas para a construção do preventório. Por aproximadamente cinco anos os trabalhos foram constantes e encheram os cofres que posteriormente se esvaziaram para a conclusão das obras. Escolas, entidades religiosas, instituições de ordem variada contribuíam. Paulo Mota e Udo Decke, engenheiros arquitetos, confeccionaram a planta do prédio e fiscalizaram a sua edificação. Grandes empresas, como a Casa Hoepcke, o Banco Popular e Agrícola, a Cia de Máquinas Singer, a Fabril Lepper, as Farmácias Minerva, as Indústrias Renaux e a Hering Textil despenderam somas vultosas em dinheiro. Os sócios das Sociedades da Assistência aos Lázaros de Santa Catarina fizeram, concomitantemente, importantes doações mensais (MATTOS, 2013).

Em 1941, quando o preventório já estava em funcionamento, havia mais de um mil e oitocentos contribuintes associados. A opção pela nomenclatura Educandário Santa Catarina em oposição a Preventório Santa Catarina esteve vinculada à intenção de diminuir os preconceitos que revestiam o abrigo, condicionados à "lepra". Porém, isso não foi suficiente para que o lugar fosse desligado dos pressupostos que permitiram a sua fundação. Na região catarinense ele jamais deixou de integrar o imaginário daquela sociedade como local de isolamento de crianças e adolescentes de pais enfermos, sendo igualmente objetos de aversão (MATTOS, 2013).

\section{Um local de amparo e exclusão}


Se é fato que a Sociedade de Assistência aos Lázaros e Defesa contra a Lepra de Santa Catarina esteve por trás da construção do Educandário; é fato, igualmente, que seu funcionamento foi entregue aos cuidados das Irmãs Franciscanas de São José. Esse quadro não foi alterado durante os seus dez primeiros anos de funcionamento, sobretudo pela experiência da congregação religiosa no trato a crianças carentes, inclusive de filhos de pais doentes, em outros lugares do Brasil e exterior (BOING, 1997). Nesse sentido, apenas a partir de 1951 a Sociedade passou a gerenciar o abrigo. Em 1969 teve seu nome modificado a título de homenagem. Iria se chamar Sociedade Eunice Weaver, continuando responsável pelo Educandário até a década de 70, quando as novas diretrizes nacionais de extinção ao sistema de isolamento já estavam em vigor. Nesse período, o abrigo foi paulatinamente encerrando o seu atendimento através do sistema de internato. Isso ocorreu em face das novas diretrizes nacionais adotadas para o tratamento da doença, agora passível de cura. Nela era previsto o fim do sistema de isolamento compulsório dos enfermos, a permissão para que os que foram internados no hospital-colônia saíssem da instituição e, consequentemente, a reintegração dos internos do Educandário Santa Catarina aos seus lares. Como desdobramento, o preventório catarinense se transformou num estabelecimento educacional aberto e direcionado a crianças carentes, ainda que tenha acolhido a filhos sadios de pais enfermos até a década de 1980 (MATTOS, 2013).

Localizado no município de Palhoça, a poucos quilômetros da capital Florianópolis, foi construído para acolher cento e quarenta crianças e adolescentes, mas chegou a contar com mais de cento e cinquenta. As verbas de sua manutenção se originavam das prefeituras de várias localidades, além dos poderes estadual e federal. Doações de associados e empresas de diferentes setores da economia continuavam sendo feitas. No entanto, a arquitetura do abrigo foi pensada para lhe providenciar um caráter de autosustentação, muito semelhante, por assim dizer, às colônias agrícolas. Nesse sentido, havia toda uma área reservada à produção de hortifrutigranjeiros destinados ao consumo interno e à comercialização que seriam viabilizados através do trabalho dos filhos sadios de enfermos que ali passaram a viver (MATTOS, 2013).

Tomado como instituição profilática sem perder de vista a importância de fomentar a educação, o Educandário promovia a alfabetização escolar amparada nas disciplinas integradas à grade curricular da época. Além disso, privilegiava a formação técnica e profissional de maneira que os internos fossem preparados ao exercício de 
diferentes atividades laborais. Esse formato de aprendizado era pensando para que eles desenvolvessem habilidades úteis dentro e fora da instituição. Isso porque muitos experenciavam uma longa estada no abrigo, alguns sendo dispensados apenas com idade superior aos dezoito ou vinte e um anos, no caso dos sexos feminino e masculino, respectivamente (MATTOS, 2013).

Sob tal perspectiva, primava-se por uma instrução adequada que era atravessada pelo preparo físico e uma boa formação cultural, agregando o cultivo aos valores cívicos, morais e religiosos, via de acesso para que fosse inculcado, nesses sujeitos, um padrão ideal de comportamento que deveria ser adotado dentro e fora da dali. Paralelamente, os internos eram fiscalizados semanalmente pelo Serviço de Profilaxia da Lepra de Santa Catarina no propósito de identificar aqueles que deixavam de ser filhos sadios para integrar a lista dos doentes. Como desdobramento, experenciava-se uma realidade extremamente traumática, uma vez que a confirmação da doença representava um novo tipo de alijamento, agora na colônia agrícola, para onde seriam enviados. Além disso, o pânico de ter a autoimagem arruinada exacerbava os temores. Sob esse aspecto os depoimentos dos egressos e das religiosas franciscanas que passaram pelo abrigo são elucidativos. A despeito da intenção de que o Educandário podia lhes oportunizar uma vida mais segura e feliz, o fato é que naquele cenário ela era marcada por estigmas, preconceito e um futuro seguramente incerto (MATTOS, 2013).

Eu sei que nós tínhamos um aluno grande lá, que era o R. De repente apresentou uma mancha no corpo e ele ficou nervoso. Era um rapaz bonito, família de Criciúma. Então o médico fez o exame, até eu estive junto. As costas... Deixou sem camisa o rapaz e fez a aplicação da plaquinha, a plaquinha quente do fogo, eles tinham uma plaquinha de vidro, não é?! Eles punham nas costas e... Mas era quente mesmo, tirado do fogo. E ele perguntou:

- Escuta, você sente quente ou frio?

Ele disse:

- Ah, é frio.

Aí depois o médico disse:

- Isto está quente, olha aqui!

Mas ele ficou desesperado, fugiu pro mato [...]. Depois, ainda altas horas da noite, lá pelas oito, nove horas, fomos lá atrás dele, procurar o rapaz no mato. Aí obrigamos a vir. Ele chorava: 
- Eu não vou pro leprosário! Não vou, não vou! (DEPOIMENTO de SB., 2002).

Nesse processo, as freiras tendiam a criar meios de impedir que os demais internos soubessem do ocorrido. Principalmente, aqueles que haviam desenvolvido, com ele, laços socioafetivos. Porém, era difícil manter o segredo e a saída do colega para o hospital-colônia acabava sendo reverberada. Assim, mesmo que muitos, ao serem levados para Educandário, se conformassem com o internamento em virtude de uma propaganda bastante sedutora e capaz de sugestionar até mesmo os pais, já que muitos eram levados a afirmar para os filhos que no preventório receberiam proteção, educação e um futuro promissor promovido pela ação de caridosas "irmãs", o certo é que qualquer discurso persuasivo não era suficiente, como sugere o depoimento de um de seus egressos.

- Minha filha, eu sempre sonhei que eu queria que você estudasse num colégio de Schwesters, de Irmãs, assim como eu frequentei, e eu não tinha condições de te dar isso lá no interior, e agora vai acontecer. Você se lembre só disso, que você vai para o lugar onde o papai sempre sonhou que tu deverias ser educada.

E aquilo eu fiquei, não é?!, na expectativa desse sonho que ele também sempre alimentou [...]. Então eu sei que, de repente veio conversar comigo aquele senhor alto, magro. Era o Doutor P. Ele disse:

- Agora nós vamos fazer um passeio bonito no meu carro.

Ele disse:

- Eu vou te levar para um lugar onde tem muitas crianças.

[...] Para mim aquela expectativa foi muito bonita. Então eu não chorei naquela hora, porque ele disse:

- O papai também está indo para um hospital onde ele vai ser muito bem tratado e ele disse pra você ficar contente porque você vai para o colégio onde ele queria que você fosse.

O exame a gente não gostava muito não. Eu tenho a impressão de que era meio constrangedor, $[. .$.$] porque a gente tinha que praticamente tirar a roupa,$ não é?! A gente ficava de costas e eles encostavam na gente, principalmente se havia alguma desconfiança, alguma mancha na pele, [...] vidrinhos com água quente e fria, e a gente tinha que dizer se sentia ou não sentia aquele 
contato. [...] E todo mundo tinha medo. Na verdade, além de ser para a gente constrangedor, apesar de a Irmã nunca deixar de estar junto, (havia) o medo de sair dali direto pro pavilhão e depois ir para a colônia. Isso era o medo, [...] de estarmos também desenvolvendo a doença.

[...] A gente ficava traumatizado. A gente sempre pensava:

- Será que eu sou a próxima?

[...] Todos nós sabíamos que tínhamos tido um período grande de convívio com os pais que estavam doentes e isso para nós não era fácil. (DEPOIMENTO de AS., 2002).

Ao analisar o livro de registro de internamentos do Educandário durante os seus dez primeiros anos de funcionamento, período em que os internos estiveram sob os cuidados da Congregação Franciscana de São José, constatou-se a passagem de trezentas e uma crianças e adolescentes pelo abrigo. Contudo, esse número extrapolou aos quinhentos até os anos 80. A maior parte teve a mãe acometida pela doença, seguindo-se pelo pai e ambos os progenitores. Houve também casos de tios, irmãos e avós, sendo os demais, sem identificação de parentesco (EDUCANDÁRIO, 1940-1950; MATTOS, 2013).

Interessante salientar, ao analisar os dados apontados, que aqueles que tiveram a mãe acometida pela doença, sobrepondo-se aos que tiveram o pai, é fato contraditório, considerando que a hanseníase tende a incidir de maneira mais frequente sobre o sexo masculino (SAMPAIO, 1984). Entretanto, ao verificar o número de enfermos que foram internados no Hospital Colônia Santa Teresa durante o mesmo período, reconheceu-se que os homens foram superiores em quantidade. Essa constatação possibilitou inferir que a maior parte dos menores era levada ao preventório quando a mãe ficava impossibilitada de provê-lo, e as razões para isso são indefinidas. Teria, o pai, então enfermo, já sido conduzido à colônia agrícola? Seria, ele, já falecido, o que impedia que os filhos ficassem sob seus cuidados?

Conjecturas à parte, a ida para o Educandário invariavelmente decorria da dissolução familiar, da incapacidade de manter a prole saudável dos enfermos em seu núcleo parental, da não acolhida de pessoas ligadas a ela por laços consanguíneos menos estreitos, atitude quase sempre associada ao medo da doença. Sob essa perspectiva, o Educandário acabava representando a solução ideal para a conformação de interesses. Os pais confiavam que seus filhos seriam bem cuidados, os parentes 
ficavam aliviados pelo desnecessário compromisso com seus entes, a sociedade se via salvaguardada porque esses indivíduos seriam afastados do convívio social, livrando os saudáveis do "perigo" iminente (GOMIDE, 1991).

E esse "perigo" vinha de todos os lados. De Santa Catarina houve internos procedentes de Tubarão, Itajaí, Florianópolis, Lages, Palhoça, Laguna, só para citar alguns exemplos. Alguns, de outros estados, como Paraná e Rio Grande do Sul. Muitos não apresentavam o local de origem e parte considerável havia saído do hospitalcolônia, frutos de uniões conjugais dadas no interior do asilo e forçosamente afastados de seus pais. A idade dos internos também sofreu variações. Assim, houve registros de zero aos dezoito anos, embora o número maior tenha se dado entre os seis e dez. Em relação ao sexo foi observada uma maior incidência para o feminino, ainda que pequena. Do tempo de permanência, pôde-se observar internos residindo por menos de um mês na instituição, conquanto que houve ocorrências de curta, média e longa duração, em que toda a infância, ou mesmo ela e a adolescência, se processaram no interior do abrigo. Com efeito, houve casos em que somente aos dezoito anos ou mais um interno passaria à categoria de egresso (EDUCANDÁRIO, 1940-1950; MATTOS, 2013). Porém, a memória de sua estada pela instituição continuava sendo lembrada nas poucas oportunidades de escolha sobre o gerenciamento de suas vidas.

Por certo, muitos desses sujeitos foram entregues a pessoas que se imbuíram de provê-los após a saída do abrigo. Eram adolescentes, em geral, já com desenvoltura para realizar atividades domésticas dentro de lares que lhes ofereciam sustento condicionado à exploração de seu trabalho. Especialmente os do sexo feminino, eram seduzidos a aceitar, quando adultos, casamentos arranjados, na justificativa de que seria difícil um matrimônio por razões afetivas em função de seu vínculo com a doença, mesmo que tivessem sido, os seus pais, os acometidos, a exemplo do depoimento a seguir:

$\mathrm{Na}$ época era um pavor, porque era uma doença bíblica, quer dizer, nos deixou, assim, marcados durante muitos anos. Hoje, por exemplo, eu falo que meu pai tinha "lepra". Pra qualquer pessoa eu falo. Antigamente eu não abria a boca pra ninguém, pra dizer que meu pai tinha "lepra", mesmo porque os nossos próprios familiares diziam que a gente não tinha escolha com relação a marido, não tinha muita escolha porque o nosso pai era doente e ninguém ia nos querer. Então, onde quer que eu fosse eu trazia sempre aquela tristeza dentro do coração, aquele receio [...], eu não falava que meu 
pai era doente pra ninguém, eu não dizia, eu não dizia que tinha um pai que tinha essa doença [...], eu tinha aquele receio de namorar, eu era muito introvertida e muito, assim, discreta no aspecto do namoro, então quando aconteceu de aparecer esse namorado, nós contamos pra ele, e não deu nada, não alterou em nada o sentimento dele. Então minha avó falou que eu deveria aceitar porque era muito difícil arrumar um namorado que fosse aceitar (DEPOIMENTO de VMM., 2002).

No âmbito do interior do Educandário, o modo austero com que eram tratados provocava a constante rememoração do lugar que ocupavam na sociedade. Mesmo em momentos festivos, em que o abrigo era aberto ao público externo, normalmente, a pessoas vinculadas à Sociedade de Assistência aos Lázaros, médicos, políticos e também à comunidade vizinha, o preconceito que revestia a doença era frequentemente evidenciado. Assim, demonstrações de afeto materializadas em afagos ou beijos no rosto eram seguidas de um apressado pedido: “ - Tem álcool, para lavar as mãos?” (DEPOIMENTO de SB., 2002).

Tal conduta evidenciava, que mesmo para indivíduos esclarecidos acerca das formas de transmissão da doença, conhecedores de que os filhos sadios dos enfermos não ofereciam risco de contágio, a praxe era evitar um contato mais aproximado. E isso era regra, inclusive, nas relações estabelecidas entre os menores e aqueles que administravam o local, a exemplo do depoimento concedido por uma das religiosas:

Era proibido [...], a gente não podia beijar uma criança, a criança beijar. Era proibido. Então, nós éramos avessas a isso mesmo, não é?

Mas eu me lembro que a criança, uma pequena então, queria muito me beijar e eu disse:

- Não! Não Pode!

[...] Depois ela trepou numa cadeira e me beijou, sabe, trepou numa cadeira e me beijou (DEPOIMENTO de SB., 2002).

O sentimento gerado a partir dessas condutas se constituía, nesse sentido, num alerta constante, fazendo com que os internos do Educandário conseguissem reconhecer quando eram, ou não, objetos de aversão. Assim, em tempos mais afrouxados, quando foi permitido a alguns o estudo profissionalizante fora do internato, em geral aos que já haviam permanecido no abrigo por um longo período sem que a doença se manifestasse, 
essa realidade se tornava mais palpável. Sob tal perspectiva conseguiam reconhecer em alguns sujeitos, principalmente de idade semelhante, a ausência de preconceitos.

O contato com outras crianças, nós mantivemos normalmente quando passamos a frequentar o colégio em São José. ${ }^{4}$ E não sentíamos isso não. Eu acho que a criança e o jovem é mais aberto, não é?! Eles tinham uma curiosidade em relação a nós, porque eles nos achavam diferentes de educação. Eles diziam:

- Vocês foram criados por freiras! (DEPOIMENTO de AS., 2002).

É provável, como percebido no depoimento acima, que as crianças alheias ao universo da "lepra" fossem menos absorvidas pelos medos que então envolviam os adultos. Mas isso não quer dizer que o preconceito deixasse de existir e que os filhos sadios dos enfermos fossem poupados de experenciá-los, em tantas outras circunstâncias. É provável, ainda, que a instituição idealizada tenha, de fato, sido concebida com o fito de amparar a prole sadia dos enfermos em virtude da doença. Porém, não há como negar que a sua concepção também foi planeada para preservar a sociedade do risco do contágio, para a qual esses sujeitos figuravam ameaça.

\section{Considerações finais}

A campanha de combate à "lepra" no Brasil e Santa Catarina, estabelecida na primeira metade do século XX, assumiu grandes proporções e afetou a vida daqueles que foram acometidos pela doença, bem como de sua prole saudável. Pautada no confinamento forçado dos enfermos em hospitais-colônias e na internação de seus filhos em instituições preventoriais, integrou um modelo de profilaxia e tratamento fundamentado na exclusão social. Especialmente acerca dos descendentes imediatos dos portadores, o privilégio às medidas de exceção vilipendiou qualquer outro instrumento de ação profilática. Assim, não houve incentivo à permanência desses indivíduos próxima de seus parentes saudáveis. Em contrapartida, deu-se o reforço aos estigmas, o que resultou na fragmentação da família, tanto aquela mais alargada, como aquela composta por seu núcleo principal. Com efeito, via de regra pais e filhos foram

\footnotetext{
${ }^{4}$ São José era um município apenso ao de Palhoça, onde havia alguns colégios que aceitavam a inscrição de internos do Educandário, a título de profissionalização (grifo próprio).
} 
separados. Os primeiros, por terem sido levados forçosamente ao hospital-colônia; os segundos, por serem internados na instituição preventorial. Mesmo que fossem engendrados eventuais encontros entre ambos, quando a Sociedade de Assistência aos Lázaros providenciava o deslocamento dos menores ao local de confinamento de seus pais, quase sempre em datas comemorativas do calendário católico; eles eram permeados por um controle excessivo que impedia a aproximação corporal. Aliás, ao que tudo indica, o afastamento de pais e filhos parecia ser intencional e buscou inviabilizar qualquer possibilidade de fuga rumo ao encontro do outro. Exemplo disso esteve na censura das correspondências que eram remetidas entre si. Tanto pais quanto filhos tinham suas cartas vetadas para que não suscitassem qualquer desejo de evasão (MATTOS, 2013).

Assim, ainda que inúmeras atividades fossem realizadas para fazer do abrigo uma instituição modelar, através do incentivo à educação técnica e profissional, à formação cultural erudita, ao aprimoramento físico, todas voltadas para uma formação exemplar; a tristeza de se ver separado dos pais, de fazer parte de uma realidade marcada por estigmas e preconceitos tornava efêmero qualquer momento de satisfação, o que dava a essa obra filantrópica e caritativa nuanças nada suaves. Por certo, ao mesmo tempo em que o Educandário Santa Catarina foi erguido sob o signo da solidariedade e da preocupação com o progresso do país; continha, em sua essência, os sentidos mais negativos que, à época, revestiam a doença. Nesse quadro, a paisagem pintada foi menos bonita para seus principais personagens: os filhos sadios de enfermos, a maior parte órfã de pais que ainda não tinham perdido suas vidas.

\section{Fontes}

ARAÚJO, Heráclides César de S. (1929). O Problema da lepra no Brasil. Boletim da Sociedade de Assistência aos Lázaros e Defesa contra a Lepra. São Paulo, vol. 1, n.9, pp.1-24, dez.

BARBOSA, Rui (1925). Higiene Escolar. Anais do IX Congresso Médico Brasileiro. São Paulo, vol. 3, pp.1-15.

DEPOIMENTO de AS. (2002), 23 abr.

DEPOIMENTO de VMM. (2002), 2 maio.

DEPOIMENTO de SB. (2002), 20 jul.

EDUCANDÁRIO Santa Catarina (1841-1983). Livro de Registros de Internamentos (1841-1883). São José, Arquivo do Educandário Santa Catarina. 
FEDERAÇÃO das Sociedades de Assistência aos Lázaros e Defesa contra a Lepra (1936). Santa Catarina: Florianópolis. Revista de Combate à Lepra. Rio de Janeiro, Ano 1, n.1, pp.7-9.

A GAZETA (1936a). Florianópolis, $7 \mathrm{dez}$.

A GAZETA (1936b). Florianópolis, 10 dez.

LEMOS, Floriano (1939). Do Isolamento dos Hansenianos. Rio de Janeiro: Typographia Baptista de Souza.

REPÚBLICA (1936a). Florianópolis, 9 dez.

REPÚBLICA (1936b). Florianópolis, 10 dez.

SOCIEDADE de Assistência aos Lázaros e Defesa contra a Lepra. Credenciais da Sociedade de Assistência aos Lázaros e Defesa contra a Lepra (1929). Boletim da Sociedade de Assistência aos Lázaros e Defesa contra a Lepra. São Paulo, vol.1, n.1, pp.3-5, abr.

. (1939). Discurso. In: Relatório de dezembro de 1937 a novembro de 1938. Florianópolis: Imprensa Oficial, pp.3-6.

TIBIRIÇÁ, Alice de T. R. (1933). Como eu vejo o problema da lepra no Brasil. São Paulo: [s.e.].

\section{Referências Bibliográficas}

ARAÚJO, Hermetes R. (1989) A invenção do litoral: reformas urbanas e reajustamento social em Florianópolis na Primeira República. Dissertação (Mestrado em História). Pontifícia Universidade Católica de São Paulo, São Paulo.

BOING, Irmã Serena (1997). Quero misericórdia: história da congregação das Irmãs Franciscanas de São José. Porto Alegre: Pallotti.

BRASIL (1995). Lei no. 9.010, de 29 de março de 1995. Dispões sobre a terminologia oficial relativa à hanseníase e dá outras providências. Diário Oficial da União, Poder Executivo, Brasília, 30 dez., Seção 1, p.1.

CHEREM, Rosângela M. (1994). Caminhos para muitos possíveis: desterro no final do Império. Dissertação (Mestrado em História). Universidade de São Paulo, São Paulo.

COSTA, Nilson R. (1985). Lutas urbanas e controle sanitário: origens das políticas de saúde no Brasil. Petrópolis: Vozes.

GIBSON, Carmencita (1965). Eunice Weaver: um símbolo. Rio de Janeiro: [s.e.].

GOFFMAN, Erving (1988). Estigmas: notas sobre a manipulação da identidade deteriorada. Trad. Márcia B. de M. L. Nunes. Rio de Janeiro: LTC.

GOMIDE, Leila Regina S. (1991) Órfãos de pais vivos: a lepra e as instituições preventoriais no Brasil (estigmas, preconceito e segregação). Dissertação (Mestrado em História). Universidade de São Paulo, São Paulo.

HOCHMANN, Gilberto (1998). A era do saneamento. São Paulo: Hucitec/Anpocs.

LENHARO, Alcy (1986). Sacralização da política. São Paulo: Papirus.

MACHADO, Roberto et al. (1978). Danação da norma: a medicina social e constituição da psiquiatria no Brasil. Rio de Janeiro: Graal.

MATTOS, Débora M. (2013). Fora do Arraial: hanseníase e instituições asilares em Santa Catarina (1940-1950). Florianópolis: NEAB-UDESC/Casa Aberta. 
MONTEIRO, Yara N. (1995). Da maldição divina à exclusão social: um estudo da hanseníase em São Paulo. Tese (Doutorado em História). Universidade de São Paulo, São Paulo.

QUEIROZ, Marcos de S. \& PUNTEL, Maria A. (1997). A endemia hansênica: uma perspectiva multidisciplinar. Rio de Janeiro: Fiocruz.

POYER, Viviani (1999). Penitenciária Estadual da Pedra Grande: estudo da instituição entre 1935 e 1945. Esboços. Florianópolis, vol. 7, pp.179-187, dez.

RAGO, Margareth (1997). Do cabaré ao lar: a utopia da cidade disciplinar. Brasil (1890-1930). Rio de Janeiro: Paz e Terra.

ROTBERG, Abraão (1975). O pejorativo "lepra" e a grande vítima de grave erro médico-social-histórico: a indefesa América Latina. Revista de História. São Paulo, ano 26, vol. 51, n. 101, pp. 295-304, jan./mar.

SAMPAIO, Sebastião de A. P. et al. (1984). Hanseníase, tuberculose cutânea e outras micobacterioses. In: SAMPAIO, Sebastião de A. P. et. al. (Orgs.). Dermatologia Básica. Porto Alegre: Artes Médicas, pp.287-309.

SANTOS, Vicente Saul M. dos (2006). Entidades filantrópicas e políticas públicas no combate à lepra: Ministério Gustavo Capanema (1934-1945). Dissertação (Mestrado em História). Casa Oswaldo Cruz/Fundação Oswaldo Cruz, Rio de Janeiro.

SHUMAHER, Schuma \& BRAZIL, Vital Érico (2001). Dicionário das mulheres no Brasil. Rio de Janeiro: Zahar.

Artigo recebido em 02 de fevereiro de 2016.

Aprovado em 19 de março de 2016.

DOI: $10.12957 /$ intellectus.2016.23838 